\title{
Time-course of location changes of visual attention
}

\author{
GARVIN CHASTAIN \\ Boise State University, Boise, Idaho
}

\begin{abstract}
The shifting of visual attention is often described as being like a spotlight moving through empty space between locations. In the present experiment, a peripheral precue summoned attention to an initial location, and $200 \mathrm{msec}$ later a second peripheral cue appeared beside a second location, $20^{\circ}$ away. The target was twice as likely to appear at the location indicated by the immediately preceding cue as it was to appear at the other location, although the second location was completely predictable from the first. A fine-grained temporal analysis revealed that as attention was shifted, sensitivity to information at the second location gradually increased while sensitivity at the first location simultaneously decreased. Sensitivity averaged over the two locations during the shift remained significantly greater than sensitivity immediately following the initial precue. An attentional spotlight moving from the first to the second location would produce a decrease in average sensitivity to its initial level while the spotlight was between locations.
\end{abstract}

A "spotlight" metaphor for the allocation of attention in visual space has gained widespread acceptance (Eriksen \& Yeh, 1985; LaBerge, 1983; Posner \& Cohen, 1984). The metaphor implies that, like a spotlight, the attentional focus must move through space to reach a new location. Posner, Walker, Friedrich, and Rafal (1984) referred to three separable components of the attention-shifting process: disengagement from the old location, movement to the new location, and engagement at the new location.

The present experiment was designed to focus on the second component, movement. Tsal (1983) conducted a study in which peripheral cues preceded targets at different intervals to indicate the target's location. Interval length and cue/target eccentricity were related to asymptotic performance to produce a velocity estimate for the movement of visual attention through empty space of $1^{\circ}$ every $8 \mathrm{msec}$. Although harsh methodological criticisms have been leveled at Tsal's study (Eriksen \& Murphy, 1987; Yantis, 1988), his estimate provides a point of reference.

Attentional movement between cued locations was assessed in the present study with the presentation of two cues, the first indicating the likely location of a target to appear within a range of very brief cue-target (interstimulus) intervals or ISIs, and the second indicating a different likely location (directly opposite fixation) if the target had not appeared within the first range of ISIs. Target identification accuracy was thus maximized by shifting attention from the location cued first to the one cued second. A control condition was included in which the two locations, which were equally likely to contain the target, were indicated simultaneously by each cue. On control trials,

\footnotetext{
An earlier version of this paper was presented at the annual meeting of the Psychonomic Society, November 1990, New Orleans. Correspondence may be addressed to Garvin Chastain, Department of Psychology, Boise State University, Boise, ID 83725.
}

no advantage accrued from shifting attention between cues, although there was a definite advantage in attending a cued location. Analyses showed that attention was being shifted, and that average sensitivity across the two locations was maintained above its initial level while attention was relocated from one to the other. Average sensitivity would have declined to its initial level during the shift if an attentional spotlight moved between locations.

\section{METHOD}

\section{Subjects}

Ten subjects, all of whom were upper-division undergraduate psychology majors naive concerning the hypothesis of the study, were paid $\$ 5 / \mathrm{h}$ for their participation. Each reported normal or corrected-to-normal visual acuity.

\section{Apparatus}

The displays, generated by an IBM PS/2 Model 30 computer, appeared on a Zenith ZCM-1490-Z analog video monitor. The decay rate of the P22 phosphor was to $10 \%$ within $1 \mathrm{msec}$. The distance between the subject's eyes and the video monitor screen was maintained at $38 \mathrm{~cm}$ with a Gulf and Western table-mounted chin cup with head restraint. Every subject's right eye was monitored continuously for movement with a closed-circuit system composed of a box camera with a macro lens connected to a television set.

\section{Stimuli}

The fixation dot subtended a visual angle of approximately $.15^{\circ}$. The hourglass figures were approximately $.9^{\circ}$ vertically and horizontally. The cues were solid squares, $.45^{\circ}$ on each side. The targets were circles, each subtending a visual angle of $.9^{\circ}$ and containing a gap $.45^{\circ}$ wide on the top, bottom, left, or right side. There were four possible target locations-approximately $10^{\circ}$ above, below, to the left of, and to the right of the central fixation dot. The masks were four squares, each with a complete circle the size of the target in its center, appearing at the possible target locations. The circles, masks, and hourglass figures were constructed with a font editor. All stimuli were bright on a black background, with the cues presented with enhanced brightness.

\section{Experimental Design}

Each subject participated in 10 criterion sessions, with each involving 560 trials, after an initial practice session of the same length. The 


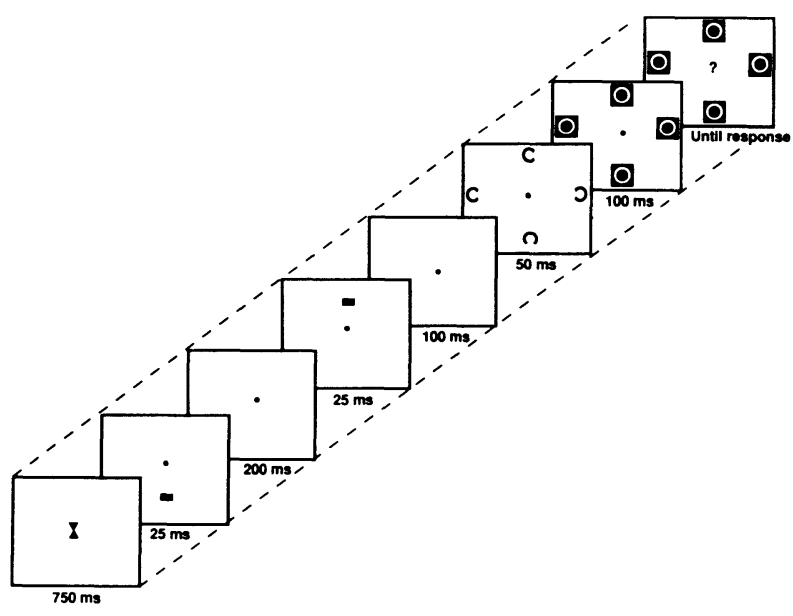

Figure 1. Sample exposure sequence with the target appearing at the location indicated by the second cue at an interstimulus interval of 333 msec.

target appeared at each of the four locations relative to fixation equally often, with the gap in each position on an equal number of trials at each location. On two thirds of the 480 experimental trials, the target was at the location indicated by the immediately preceding cue, and on one third it was at the opposite location. On the 80 control trials, both locations on an axis were cued simultaneously, with the target then appearing at one of them. Each ISI and axis was represented equally often for both experimental and control trials. All orders were completely randomized within each session.

\section{Procedure}

At the beginning of each trial, an hourglass figure was presented for $750 \mathrm{msec}$ at fixation. Its indentations were either at the left and right or at the top and bottom to indicate the possible sides on which the gap could appear in the target circle for that trial. The hourglass figure was replaced immediately by the fixation dot, which remained present throughout the remainder of the exposure sequence. For experimental trials, the first cue appeared with the dot, $9^{\circ}$ from fixation, for $25 \mathrm{msec}$, with a second cue to follow after a brief delay. The first and second cue always appeared on the same axis relative to fixation (above/below, or left/right); the first cue appeared at a given location on $50 \%$ of the experimental trials for that axis. On control trials, squares appeared at both possible locations within an axis as the first and second cues. The target display contained four circles, one at each possible target location. On the cued axis, one circle contained a gap on one of two sides indicated by the hourglass, and the other contained a gap on one of the other two sides. On the uncued axis, each circle contained a gap on one of the sides (chosen randomly) indicated by the hourglass. The target display was present for $50 \mathrm{msec}$ and was masked immediately upon its offset. The target display could follow the first cue after $0,50,100,150$, or $200 \mathrm{msec}$; or instead, the target display could appear after the second cue, present for $25 \mathrm{msec}$ at an ISI of $200 \mathrm{msec}$ after the first cue and directly opposite fixation from it. In this case, the target display followed after $0,50,100,150$, or $200 \mathrm{msec}$ (at ISIs of 225, 275, 325, 375 , or $425 \mathrm{msec}$ with respect to the first cue). If the target display had appeared during the first range of ISIs, masks were present with and following the second cue (if the target appeared at an ISI of $200 \mathrm{msec}$, the second cue appeared at an ISI of $250 \mathrm{msec}$ ). The final display contained the masks and a question mark at fixation. For both experimental and control trials, the two axes were relevant on an equal number of presentations. A sample exposure sequence is given in Figure 1.

The subject responded by pressing an arrow key on the numeric keypad of the computer's keyboard to indicate the position of the gap on the target (top, bottom, left, or right side). If an impermissible response (one not consistent with the information from the hourglass) was made, the computer emitted a beep and the subject gave a permissible response.
Feedback at fixation immediately followed for $750 \mathrm{msec}$. The screen then went black for approximately $2 \mathrm{sec}$ while the computer recorded information about the exposure and response and prepared the displays for the next trial, and the next trial proceeded. The subjects could take a break by withholding the response until ready.

\section{RESULTS}

All subjects produced eye movements during initial practice sessions, ranging from 2 to 56 movements per subject. Two subjects were dropped after the first session, 1 for not having achieved overall target identification accuracy of $55 \%$ (chance $+.1 \times$ chance), and the other for an excessive number of eye movements (movement was detected on $10 \%$ of the trials). Perhaps because a stern admonition followed any eye movement during practice, no eye movement was detected for any subject during any exposure sequence in the criterion sessions.

The proportion of responses correct for each gap position (top/bottom and left/right), ISI, and location (cued first/second) for each subject were converted to $d^{\prime}$ measures. Analysis of variance indicated as significant the effect of ISI $[F(9,63)=3.61, p<.005]$, as well as the ISI $\times$ location interaction $[F(9,63)=13.96, p<.001]$. Gap position produced no significant main effect or interaction involving location (all $p s>.10$ ). Means are plotted in Figure 2. A Tukey (a) post hoc test revealed significant location effects at ISIs of 50, 100, 150, 325, 375 , and $425 \mathrm{msec}$.

Analysis of average sensitivity in experimental conditions versus sensitivity on control trials at each ISI yielded as significant the effect of ISI $[F(9,63)=3.91, p<.001]$, as well as the interaction between ISI and experimental/ control $[F(9,63)=3.05, p<.005]$. Means are plotted in Figure 3. A Tukey (a) post hoc test revealed a significant difference at ISIs of 50 and $425 \mathrm{msec}$. Planned com-

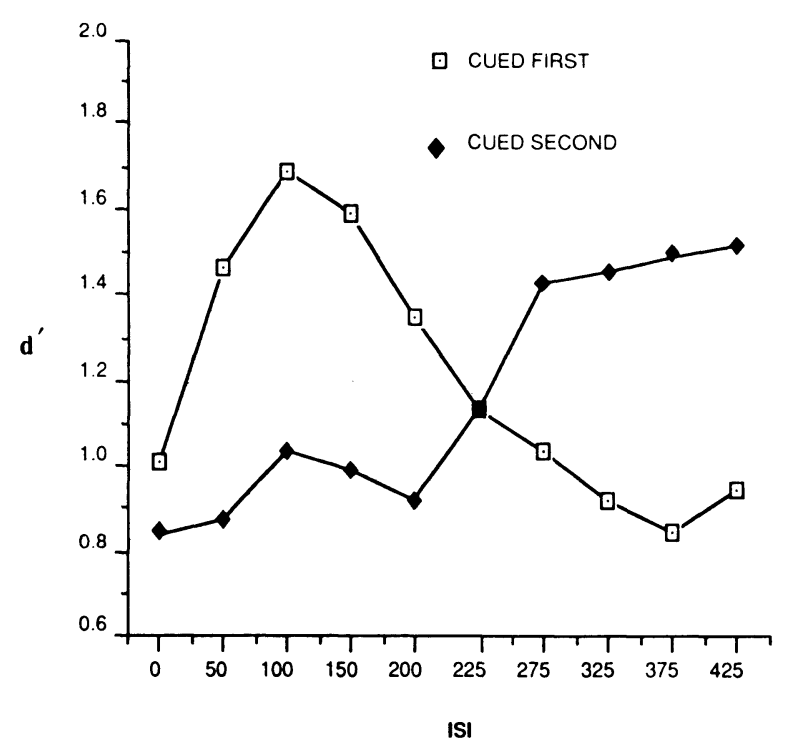

Figure 2. Mean sensitivity across interstimulus intervals (ISIs) for the locations cued first and second in the experimental conditions. 


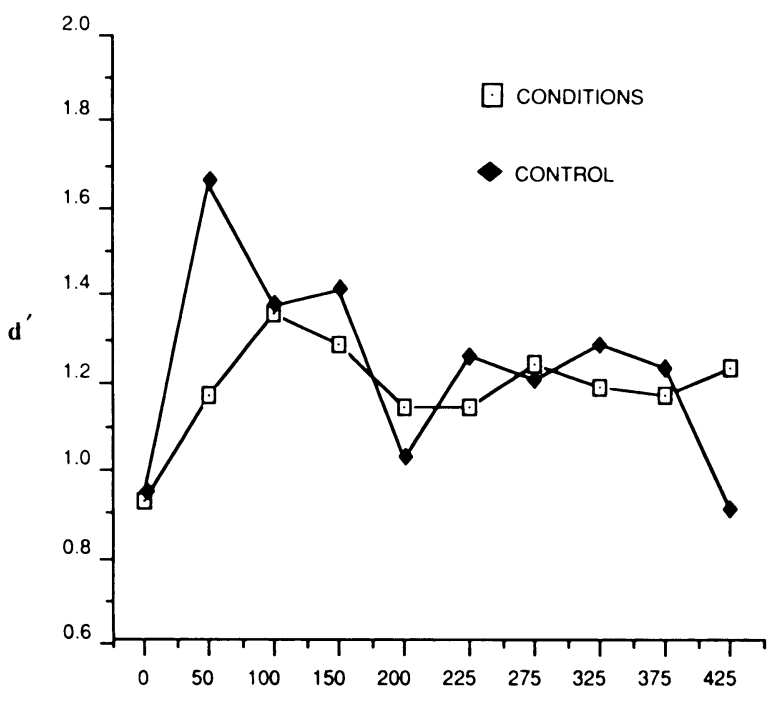

ISI

Figure 3. Mean sensitivity across interstimulus intervals (ISIs) for the mean of the experimental conditions and the control trials.

parisons for the experimental conditions between sensitivity at ISI $=0$ and ISIs in the middle of the range at which there was no significant effect of location in the first analysis $(200,225$, and $275 \mathrm{msec})$ showed significant differences at each (all $p s<.05$ ).

At no ISI within the control trials did mean proportion correct exceed .75 (the expected maximum if attention were completely allocated to one location, resulting in perfect accuracy for targets appearing there and chance accuracy at the other location), with the largest $[t(7)=1.22$, $p>.10]$ at $50 \mathrm{msec}$. Also, at no ISI within the experimental conditions did overall mean proportion correct exceed .833 (the expected maximum if attention were completely allocated to the location indicated by the immediately preceding cue). The overall mean proportion of responses correct was .711 .

\section{DISCUSSION}

Sensitivity at the two locations on the relevant axis was not significantly different immediately after the appearance of the first cue (ISI of $0 \mathrm{msec}$ ); it then rose at the location cued first and peaked at an ISI of $100 \mathrm{msec}$ (see Figure 2). The effect at short ISIs is consistent with that observed by other researchers (Eriksen \& Collins, 1969; Eriksen \& Rohrbaugh, 1970).

Sensitivity at the location cued first began declining before the appearance of the second cue. Muller and Findlay (1988) found a similar decline between 100 - and 200 -msec delays in target-identification accuracy at a single precued location, which they related to Posner and Cohen's (1984) inhibition effect. The effect is such that inhibition, as well as facilitation, develops at a cued location to minimize reattending to that location in the visual field. Facilitation predominates immediately upon attending to a given location, but the facilitation dissipates rapidly and makes the inhibition at that location evident. In Figure 2, a slight sensitivity decline at the location cued second also is apparent from 100 to $200 \mathrm{msec}$, sug- gesting that the location cued second was occasionally, but not often, attended after the first cue. Sensitivity at the location cued second rose upon the appearance of the second cue to be significantly greater than at the location cued first by an ISI of $325 \mathrm{msec}(100 \mathrm{msec}$ after the offset of the second cue, slightly longer than the delay producing a significant sensitivity difference at the location cued first).

A comparison of average sensitivity across ISIs in the experimental conditions and that in the control trials (Figure 3 ) shows no relative decline for the former after 150 and before $325 \mathrm{msec}$, when attention would be shifted from one location to another in the experimental conditions. Instead, as the tradeoff apparent in Figure 2 suggests, average sensitivity at the two locations was maintained across this range of ISIs at a level that is greater than sensitivity at zero ISI, which might be considered a baseline for sensitivity when attention is unlikely to be allocated to the target location. Since the locations were $20^{\circ}$ apart, Tsal's (1983) attentional velocity estimate of $1^{\circ}$ every $8 \mathrm{msec}$ would lead to a prediction of a dip to baseline persisting for approximately $160 \mathrm{msec}$ in the average sensitivity function for the experimental conditions. It may be worth noting that lateral masking produced by any afterimage of the first cue on targets appearing at zero ISI appears to be minimal (Wolford \& Chambers, 1983), for there is no decline in sensitivity at an ISI of $225 \mathrm{msec}$, immediately after the appearance of the second cue.

The rise in sensitivity on the control trials above that for the experimental conditions at an ISI of $50 \mathrm{msec}$ suggests that it may be possible to determine the relevant target circle on the cued axis preattentively if neither circle is cued specifically, although the effect is extremely shortlived (Neisser, 1967). This sensitivity spurt appears $50 \mathrm{msec}$ earlier than the ISI producing maximum sensitivity in experimental conditions at the location cued first, and providing evidence that the two effects do not have same cause.

It is difficult to conceive of a way in which small undetected eye movements could have produced the observed pattern of results. There probably was not enough time for an eye movement toward the location cued first (Alpern, 1972). It might have been possible to detect the first cue and then move the eyes in the opposite direction toward the location cued second after around $200 \mathrm{msec}$. However, eye movement would have caused retinal smearing and saccadic suppression (Chekaluk \& Llewellyn, 1990), lowering sensitivity on trials on which the target appeared during or immediately after the move and producing a dip in the average sensitivity curve at the intermediate ISIs.

The results clearly indicate that there is no true movement of attention through empty space from one location to another. When attention is realigned, it merely builds at the new location while simultaneously declining at the old one.

\section{REFERENCES}

AlPern, M. (1972). Eye movements. In D. Jameson \& L. M. Hurvich (Eds.), Handbook of sensory physiology: Vol. 7. Sensory psychophysics (pp. 303-330). Berlin: Springer.

Chekaluk, E., \& Llewellyn, K. R. (1990). Visual stimulus input, saccadic suppression, and detection of information from the postsaccade scene. Perception \& Psychophysics, 48, 135-142.

Eriksen, C. W., Collins, J. F. (1969). Temporal course of selective attention. Journal of Experimental Psychology, 80, 254-261.

ERIKSEN, C. W., MURPhy, T. D. (1987). Movement of attentional focus across the visual field: A critical look at the evidence. Perception \& Psychophysics, 42, 299-305.

Eriksen, C. W., Rohrbaugh, J. W. (1970). Some factors determining efficiency of selective attention. American Journal of Psychology, 83, 330-342.

ERIKSEN, C. W., \&EH, Y. (1985). Allocation of attention in the visual field. Journal of Experimental Psychology: Human Perception \& Performance, 11, 583-597.

LABERGE, D. (1983). The spatial extent of attention to letters and words. Journal of Experimental Psychology: Human Perception \& Performance, 9, 371-379.

Muller, H. J., \& Findlay, J. M. (1988). The effect of visual atten- 
tion on peripheral discrimination thresholds in single and multiple element displays. Acta Psychologica, 69, 129-155.

NeIsSER, U. (1967). Cognitive psychology. New York: AppletonCentury-Crofts.

Posner, M. I., \& CoHen, Y. (1984). Components of visual orienting. In H. Bouma \& D. G. Bouwhuis (Eds.), Attention and performance $X$ (pp. 531-555). Hillsdale, NJ: Erlbaum.

Posner, M. I., Walker, J. A., Friedrich, F. J., \& Rafal, R. D. (1984). Effects of parietal injury on covert orienting of attention. Journal of Neuroscience, 4, 1863-1874.
Tsal, Y. (1983). Movements of attention across the visual field. Journal of Experimental Psychology: Human Perception \& Performance, 9, 523-530.

Wolford, G., \& Chambers, L. (1983). Lateral masking as a function of spacing. Perception \& Psychophysics, 33, 129-138.

Yantis, S. (1988). On analog movements of visual attention. Perception \& Psychophysics, 43, 203-206.

(Manuscript received April 1, 1991.)

\section{The Second International Conference on Music Perception and Cognition University of California, Los Angeles February 22-25, 1992}

The Second International Conference on Music Perception and Cognition (2nd ICMPC) will be held, under the auspices of the Society for Music Perception and Cognition (SMPC), at the University of California, Los Angeles (UCLA) February 22-25, 1992. The Conference follows the highly successful first conference held in Kyoto, Japan, in October 1989. The 2nd ICMPC will provide an open forum for work in all areas of music perception, cognition, and related disciplines. There will be symposia of interest to a general audience and sessions of particular interest to specialists. Concerts and performance of all types of music, including non-Western, will be staged.

The conference welcomes a full range of research and scholarship, including experimental, theoretical, musicological, ethnomusicological, acoustical, physiological, and computational, which are directed toward the musical mind. In addition, performances of compositions that are based on these domains, or lecturerecitals including recorded tapes, are encouraged.

Abstracts of roughly 250 words should be submitted by September 30, 1991. Contributed papers are welcome. All papers should describe work that has not been presented at a conference or published in a journal. Proceedings will be published in consultation with the SMPC.

For further information, please contact Roger A. Kendall, 2nd ICMPC Secretariat, Department of Ethnomusicology and Systematic Musicology, 1642 Schoenberg Hall, UCLA, Los Angeles, CA 90024 (telephone, 213-206-6080; FAX, 213-206-6958). 